\title{
Development of the Emerging Theory of Encountering Nursing in a Nurse-Nursed Dyadic Relationship (ThENNDyR)
}

\author{
Jose Mari Louis Alforque ${ }^{1}$, Raza Crecia Meneses², Miralou Sorronda3 ${ }^{3}$, Rozzano C. Locsin${ }^{4 *}$ \\ ${ }^{1}$ College of Nursing, Cebu Normal University, Cebu, Philippines \\ ${ }^{2}$ Visayas State University, Baybay, Philippines \\ ${ }^{3}$ Jose Rizal Memorial State University, Katipunan Campus, Katipunan, Philippines \\ ${ }^{4}$ Tokushima University Graduate School of Biomedical Sciences, Tokushima, Japan \\ Email: alforquej@cnu.edu.ph, razameneses@vsu.edu.ph,mimicuenca39@gmail.com, ${ }^{\star}$ locsin@tokushima-u.ac.jp
}

How to cite this paper: Alforque, J.M.L., Meneses, R.C., Sorronda, M. and Locsin, R.C. (2020) Development of the Emerging Theory of Encountering Nursing in a NurseNursed Dyadic Relationship (ThENNDyR). Open Journal of Nursing, 10, 777-809. https://doi.org/10.4236/ojn.2020.109056

Received: August 10, 2020

Accepted: September 11, 2020

Published: September 14, 2020

Copyright $\odot 2020$ by author(s) and Scientific Research Publishing Inc. This work is licensed under the Creative Commons Attribution International License (CC BY 4.0).

http://creativecommons.org/licenses/by/4.0/ (c) (i) Open Access

\begin{abstract}
Encounters are celebrated experiences between persons with connectedness in human situations as expectation. While being in a human dynamic and rhythmic interaction, nursing encounters are dyadic relationships illuminated as patterns of an interconnected relationship moving between the nurse and the nursed, and reflecting person-and-otherness events. The purpose of this paper is to describe the theory of Encountering Nursing in a Nurse-Nursed Dyadic Relationship (ThENNDyR) and to illuminate the four nursing practice processes on which the theory is founded: Knowing as appreciating relational moments, Reflecting as engaging moments, Realizing as patterns of living moments, and Transcending as celebrating moments. Nursing practice occurs in moments in which dyadic relationships transpire as nursing encounters. As fleeting as moments are, the four processes of nursing simultaneously take place as understanding conditions that the who and what of the person warrants persons. "Encountering nursing" is a momentary co-existence of persons in a person-and-otherness situation communicating connectedness-interconnectedness in distinct patterning. Interactions in nursing exist as persons remain wholes and complete in the moment.
\end{abstract}

\section{Keywords}

Dyadic Relationship, Knowing, Nursing Encounter, Reflecting, Transcending, Nursing Theory, Nursing Practice 


\section{Introduction}

Every day nurses encounter different individuals with varied health-related conditions, all with different backgrounds, different concerns, and different stories. Every nursing encounter is a unique experience. The nursed as patients are persons, and despite the conditions and the circumstances they experience, they will always remain whole persons, a perspective that all nurses ought to embrace. Therefore, any individual whom a nurse encounters (in multiple ways) is a person to be "nursed," requiring nursing in multifarious ways.

Nursing occurs in person-otherness situations in which the nurse and person being nursed in dyadic relationships affirm, celebrate and support who and what they are as persons. The theory assumes a relationship of person-otherness is represented by the nurse and the person being nursed in a dyadic relationship, comprised of two entities, here being the nurse and the person being nursed. Every nursing encounter between the nurse and the nursed is a unique experience that happens from moment to moment, an experience that should be lived and relived to fully grasp the essence of nursing practice.

A nursing encounter as a dyadic relationship is relating-to know persons more fully as persons. A dyadic relationship-comprised of two entities namely the nurse and the person being nursed-is a relational approach in which human beings are regarded as inherently relational; an approach in which human beings become fully engaged in practice through relationships with others, and in which persons have the capacity to establish meaningful relations with others [1]. The concept of nursing encounters values the uniqueness of each person in a direct, mutual and open relation between persons and the fullness and presence of humanity that is honored and embraced [2]. The capacity for dialogical relating gives special meaning to human existence [3], and the communion between the nurse and the nursed in the encounter can be characterized by equal perspectives, meeting each other on the same level [4]. The nurse and person being nursed are active participants in the encounter wherein the nurse illuminates hope while living and growing in their nursing encounter. While the nursed desires to be understood and known, the nurse is ever-present as expected in the encounter [5].

\subsection{Purpose}

The purpose of article is to describe the development of the theory of Encountering Nursing in a Nurse-Nursed Dyadic Relationship. This theory was aimed at illuminating the essence of encountering nursing in practice for persons in any given moment.

\subsection{Definition of Terms}

Dyadic Relationship is the significant, mutual relationship between the nurse and the nursed. The nurse and the nursed both have a role to play in forming a therapeutic dyadic relationship that brings about the desired outcome [6]. The 
dyadic relationship between the nurse and the nursed is a synergistic, evolving process [7] for the purpose of freely and consciously steering the interactions toward a therapeutic or nontherapeutic relationship.

Helping Environment depicts the kind of environment that fosters growth in a person (see Figure 1). This environment is significant to both the nurse and the nursed as it affects the wholeness of a person. It is an engagement or a dialogue, more of a stronger movement of interconnectedness with a deeper sense of meaningful relations between the nurse and the person being nursed in the full appreciation of the oneness of persons.

Nurse is a person who is whole in the moment, a healthcare professional considered as the facilitator of the nursing experience.

Nursed is a term for the person who is a participant in the nursing experience rather than recipient of it. This is an individual who is whole moment to moment. Boykin and Schoenhofer [8] noted that "being complete in the moment signifies that there is no insufficiency, no brokenness, and no absence of something; that wholeness, or the fullness of being, is forever present." They are termed as "nursed" rather than patient or client since they are not mere recipients of care, rather, they are participants in the caring experience.

Nursing Encounter is an encounter between two equal persons where one is the nurse and the other is the person being nursed, in which there is a sense of mutuality, true presence, and with both having allowed themselves to be the person they are.

\subsection{Limitation}

As a developing and emerging theory of nursing focused on the relationship between the nurse and the person being nursed, and as a middle range theory, it has limited application, currently only for adult persons. Further development of the theory is expected to include other persons, e.g. children, older adults, persons with vulnerabilities, and expectant mothers. Advancing the theory is critical to its value as a significant contribution to the discipline and profession of Nursing.

\section{The Theory Development Process}

One better way to advance knowledge in nursing is to create and develop nursing theories that describe a certain nursing phenomenon and practice processes that are distinctive for particular phenomena. There are existing nursing theories that guide nursing practices. However, with distinctive phenomena inspiring the development of the discipline and profession of nursing, nursing theories ought to ascertain occurrences that influence the perspective of enhancing human health and well-being.

Theory development in nursing is an essential component of nursing scholarly endeavors undertaken to advance the knowledge of the discipline [9]. Any nursing theory that clearly advances the understanding of nursing phenomena 
guides these developments to further inform the science of nursing and its practice. Through rigorous research, as in other disciplines, engaging in research undertakings is a way of advancing disciplinary knowledge aimed at legitimizing the social and professional contributions of the discipline.

Once a nursing theory addresses a phenomenon of interest, several considerations are deliberated, such as its completeness and logical consideration, internal consistency, and correspondence based on empirical findings, as well as whether it has been operationally defined for testing. Hardin \& Bishop [9] pointed out that it is important to understand the concept of systematic development as an approach to construction of theory. One common concern is that theory development has to be done in a precise and systematic manner, making the stages of development explicit. This approach is essential to the advancement of nursing theory development and continuously influences its development.

An understanding of selected scholarly terms, definitions, and assumptions is required in theory development. Scholarly reviews and analyses are prominent requirements, while attention to terms and defined meanings are recognized to enhance understanding of the development process. As one constructs and develops a theory, the clarity of terms and their scientific utility and value to the discipline are critically appreciated as processual considerations.

\section{Concept Analysis and Basic Elements}

Concept analysis is a process of examining the basic elements of a phenomenon or concept [10]. Knowing "what counts" when describing a concept helps in distinguishing concepts from those which may be similar in usage. In concept analysis simpler elements are targeted, thereby making the concept easier to understand, including its structure. Concept analysis is an important initial step in the process of theory development for the purpose of developing a conceptual definition [10]. It is crucial that concepts are defined clearly to eliminate ambiguity in the given concept or set of concepts. To eliminate perceived differences in meaning, explicit definitions are necessary. Nuopponen [11] noted that if the researcher notes a lack of clarity surrounding a concept, a concept analysis should be undertaken to achieve a better understanding of the concept. As the theory progresses in its development, theoretical and operational definitions provide the theorist's meaning of the concept and the basis for empirical indicators [10].

Theories are examined from realistic viewpoints; therefore, the concepts must be linked to operational definitions relating the concepts to observable phenomena and specifying empirical indicators. For example, in the ThENNDyR, the concept of nursing encounter is explored. This concept already exists in nursing; however, in the theory being developed nursing encounter is described within a nurse-nursed dyadic relationship. What then, is significant about nursing encounter within the ThENNDyR?

A process of concept analysis by Wilson (1963) [10] instigated the movement 
to analyze data, and establish a classic concept. Wilson's methodology is comprised of eleven steps but was later modified and simplified into eight steps which were believed sufficient to capture the essence of the process [10]. The steps are as follows: 1) Select a concept; 2) Determine the aims or purpose of analysis; 3) Identify all uses of the concept; 4) Determine the defining attributes; 5) Identify model cases; 6) Identify additional cases; 7) Identify antecedents and consequences; and 8) Define empirical referents.

As such, concept analysis clarifies the symbols (words or terms) used in communication, and the main advantage of concept analysis is the rendering of a very precise theoretical framing and operational definitions for use in theory, practice and research. This also applies to nursing, as concept analysis can help clarify the terms used in nursing. Its utility for tool development and nursing language development is an advantage. The rigor of concept analysis is an extremely good practice in a growing discipline and profession such as Nursing.

\section{Philosophical-Theoretical Underpinnings of the Theory}

The phenomenon of concern in the theory of Encountering Nursing in a NurseNursed Dyadic Relationship is "encountering Nursing" in practice. Viewed from existentialist and humanistic philosophical perspectives, the theoretical and conceptual grounding was established through the theory of Nursing as Caring by Boykin and Schoenhofer [8], Locsin's [12] Technological Competency as Caring in Nursing, and Parse's [13] Theory of Human Becoming. The elemental attributes and conceptual descriptions encompassing the foundations of the emerging theory are described below.

The philosophical background is discussed as follows: Existentialism is a $20^{\text {th }}$ century philosophical perspective that rejects the notion of the universe offering any clues about how humanity should exist [14]. It is centered on the analysis of existence and of the way humans find themselves coexisting in the world. A simplified understanding of this thought system can be found in Jean-Paul Sartre's [15] often repeated dictum, "Existence precedes essence." The impression is that humans exist first and then each individual spends a lifetime changing their essence of nature. It is a philosophy concerned with finding self and the meaning of life through free will, choice, and personal responsibility. The belief is that people search to find out who and what they are throughout life as they make choices based on their experiences, beliefs, and outlook. An existentialist believes that a person should be forced to choose and be responsible without the help of laws, ethnic rules, or traditions [16].

With many existentialist viewpoints emerging during the time of Sartre, there came a point when existentialism had so many definitions that it could no longer be defined [17]. As Sartre [15] himself said, the word existentialism has been so stretched and took on so many broad meanings, it no longer means anything at all. Thus, existentialism was better described as a tendency or attitude with a few doctrines common to all its exponents [15] (in [18]). 
Humanism, however, is a philosophy that focuses on the freedom, dignity, and potentials of human beings with a central assumption that people act with intentionality and values [19]. This notion is in contrast to the behaviorist impression of operant condition, which argues that all behavior is a result of the applications of consequences, and the cognitive psychologist's belief that knowledge discovery or meaning construction is central to learning. Humanism also believed that it is necessary to study the person as a whole, especially as the individual grows and develops over their lifespan. David [20] noted that humanism follows the study of self, motivation and goals which are areas of particular interest in nursing and its practice.

\subsection{Theories Underpinning the Theory}

In Boykin and Schoenhofer's [8] Nursing as Caring theory, the view of the person is that human beings are unpredictable and always complete moment to moment, not needing any fixing or to be made whole again. Persons throughout their lives, grow in their capacity to express caring. The assumption that "all persons are caring by virtue of their humanness" sustains the acceptance of persons as "fundamentally, potentially, and actually caring" ([8], p. 2). The belief that "all persons are caring" involves a commitment to know self and other as caring persons.

However, Locsin [12] in his theory of Technological Competency as Caring in Nursing, pointed out that viewing persons as whole is critical to the appreciation of contemporary professional nursing practice. The ultimate concept is understanding nursing practice as the nurturance of persons and not the task of fixing them or making them whole again. An assumption of the theory declares that persons are always wholes regardless of missing human parts [12]. Mutual and continuous knowing of persons is expressed as the intentional and authentic "knowing of persons as caring" [12]. However, in "knowing persons as caring," the nurse uses all possible ways and means available as calls for nursing for the origination and implementation of responses to these calls for nursing [12].

Altogether, these nursing practices provide the nurse with continuous opportunities to know persons fully as caring while remaining whole and complete human beings. The nurse must be able to view the person as someone unique through his or her hopes, dreams, and aspirations that are distinctively their own ([12], p. 94).

Nevertheless, the Human Becoming theory of nursing [13] presents an alternative to both the conventional bio-medical approach and the bio-psycho-social-spiritual (but still normative) approach of most theories of nursing. The human becoming theory posits quality of life from the person's own perspective as the goal of nursing practice. Parse contends that humans are irreducible to their component systems or parts and can still be understood. Persons are living beings who are more than and different from any schemata that divide them. Parse departs from the traditional medical view of nursing and proposes to distinguish nursing as a 
discipline that is unique and apart from any other discipline, as a basic science. Parse supports the notion that nurses require a unique knowledge base that informs their practice and research and this knowledge (of the human-universehealth process) is essential for nurses to fulfill their commitment to humankind [13] [21] [22] [23].

Tomey \& Alligood [21] noted from the concepts of Parse [13] that humans are intentional beings in that they have an open and meaningful stance with the universe and the people, projects, and ideas that constitute lived experience. $\mathrm{Hu}$ man beings are intentional in that their involvements are not random but chosen for reasons known and not known. Thus, anchoring his view on existential-phenomenological thought, Parse drew on the tenets of intentionality as human subjectivity and the corresponding concepts of co-constitution, co-existence, and situated freedom [13] [21].

\subsection{Paradigmatic Basis of the Theory}

Newman, Sime \& Corcoran-Perry [24] noted that the unitary-transformative perspective is a significant paradigm declaring a shift of a perspective in which a phenomenon is viewed as a unitary, self-organizing field embedded in a larger self-organizing field, which is identified by patterns and by interaction with the larger whole. In this re-organization of views, change is unidirectional and unpredictable as systems move through stages of organization and disorganization to more complex organization. Knowledge is personal, involves pattern recognition, and is a function of both viewer and the phenomenon viewed. The subject matter includes thoughts, values, feelings, choices, and purpose, while inner reality depicts the reality of the whole. Viewed from this angle of perspective, caring in human health experience would be studied as a unitary-transformative process of mutuality and creative unfolding.

In a unitary-transformative perspective, the focus to be studied is the indivisible whole. This perspective is very much particular in considering the "wholeness" of a person in relation to time and space. As such, a person will always be and will remain to be whole and encounters between the nurse and the nursed constitute an opportunity to fully understand the who and the what of a person for the appreciation of the person which occurs from moment to moment. Knowledge from a unitary-transformative perspective is more difficult to characterize, in the sense that an example generated from this perspective might be an understanding of the synchrony and mutuality of nurse-client that transcend the time and space limitations of a present situation.

\subsection{Significance of the Theory of "Encountering Nursing"}

Fundamentally, the different areas where a nurse is provide a wide array of opportunities to expand and enhance their knowledge, skills and attitude in the practice of safe and quality patient care. Related learning experiences across varied nursing settings are important throughout a nurse's career-whether as a 
student or as experienced, licensed nurses-because they provide a career path to patient care decisions and professional career development. Without this, nurses are neither able to justify their roles and responsibilities in an autonomous role as patient advocates, nor to contribute to global healthcare initiatives [25].

From time to time, nurses face different persons from all walks of life and with every person there is a certain degree of interaction and a unique experience leading to a meaningful encounter. To fully understand the practice and the profession, a dyadic relationship between a nurse and the nursed helps in developing growth in the caring experience and a transformational journey that transpires in both persons.

The search for patterns and meaning should extend to the roles and processes nurses engage with. To function as holistic healers, nurses must look for patterns and meanings within the persons being cared for. For example, nurses who practice holistically believe pain and disease are important signals of inner conflictsthat our bodies are dynamic, multidimensional systems and that disease or disability is a process best understood within the context of meaning and personal values [26]. The encounter between registered nurses and persons in need of healthcare has been described as fundamental in nursing care [27]. Being personal and professional at the same time could encourage nurses to focus on doing and being during the encounter.

\subsection{Assumptions of the Theory of Encountering Nursing}

The structure of the theory is substantiated by four assumptions. These assumptions are:

\subsubsection{Persons Are Whole Beings in the Moment}

Persons as human beings are viewed as wholes or complete in the moment. As such, there is no need to fix them or make them whole again [12]. Inherent in humans as unpredictable, dynamic, and living beings is the regard for self as a unique person.

\subsubsection{Persons Who Are Being "Cared For" Have the Need to Be "Known For"}

The unique understanding of what is being "cared for" is that it focuses on the experiences of the patient or the one being nursed [28] rather than the nurse alone. As nursing science continues to expand, the most important questions should focus on what nurses know rather than on what they do [29]. Knowing persons is a continuous process of mutually "appreciating, celebrating, supporting, and affirming" each other as participants of care [28]. Importantly, knowing the "who" and "what" of patients helps to make concrete the fact that people are more than simply a physiochemical and anatomical beings [12]. Knowing persons allows the nurse to know who the person is, the nurses' intention to care [30] implies a continuing appreciation of the ever-changing person-never static, but rather dynamic. 


\subsubsection{Persons in Interactive Moments Remain Whole Beings}

Persons are immersed in a web of ongoing relationships and being "in relation" to another is a fundamental part of human existence [31]. Persons are defined by their historical connections and relationships. The recognition of a person's history acknowledges their social, psychological and cultural biography, and in acknowledging this biography, development continues through the life-span, "forming the tapestry of one's life" [32]. A person's reality refers to the everyday world. It is imbued with personal meanings, beliefs, and values which are essential to the way the person "sees" themselves and the way their world is constructed. Whilst many aspects of an individual's reality may be shared with others so that common understandings can exist in order to form a sense of community, it is the individuality of our personal meanings that determines "who I am".

\subsubsection{Every Nurse-Nursed Encounter Is a Mutual Interaction}

Communication is the two-way process of reaching a mutual understanding, in which participants not only exchange information, ideas and feelings but also create and share meaning. In general, communication is a means of connecting people. This happens when we see communication as a ways of connecting and understanding one another-when we start using empathy and our other senses to really understand where the person is coming from and what are they trying to say. People have different life experiences that make us have different points of view. Communication involves understanding why someone is saying what they are saying and why is it so important to them. Mutual communication brings us many situations such as mutual understanding, happy feelings, smiles, love, new ideas, and something better like those benefits one could not get through one-way communication. In communicating with an "other" a shared exchange of information occurs within a realistic and true presence [33].

However, presence is an elusive concept in nursing practice that has been recognized as advantageous in the patient experience [34]. Nursing presence, defined as genuine and meaningful exchange between the nurse and the patient, is believed by certain scholars to be the core of nurse-patient relationship [35] [36]. The concept of presence goes beyond face-to-face contact with the patient, but presence in its multitude of meanings may be one of the greatest essential therapeutic components, indispensable to quality nursing care [36]. Presence in nursing, in any given nursing encounter, is an integral and mutual exchange among nurses and patients that involves attentiveness, empathy, and the mature recognition of the nurse's and the patient's needs [36]. A strong view expressed in the literature is that face-to-face encounter is important and cannot entirely be replaced by remote encounters.

\section{Theoretical Attributes of the Theory of Nurse-Nursed Dyadic Relationship}

Attributes are those characteristics that repeatedly appear in a concept and help researchers differentiate the occurrence of a specific phenomenon from a similar 
one that guides in describing the concepts in the theory development process [10]. Knowing more about the attributes associated with meaningful nursing encounters makes it possible for nurses to individualize care for persons being nursed (patients) and makes it easier to facilitate help and support the nursed in what they most need, and making them participate in their care [37]. As foundational to theoretical development, four attributes are identified and described, namely: Presence as comforting presence; Interconnectedness as facilitating togetherness; Mutuality as engaging exchange of self; and Mindfulness as transforming nursing experience. A multitude of identified characteristics exist that describe a nurse in any situation of care. As a way to advance knowledge in this theory, attributes are identified to better understand the distinct characteristics of the nurse that will take shape in all processes of nursing, focusing on what is central to the theory which is a dyadic relationship in nursing encounters.

Defining attributes, similar to signs and symptoms, are critical characteristics that help to differentiate one concept from another related concept and clarify its meaning [38] [39]. These attributes characterize the image exhibited by the nurse in every process of nursing. These are characteristics inherent in a nurse which may either be practiced or not, enhanced, learned or nurtured as situated in the processes of nursing. Knowing these attributes gives the nurse a distinct imagery in nursing encounters among the many characteristics of being a good nurse. These attributes transcend expectations of the process of nursing as guides for illuminating the meaning of nursing encounters.

\subsection{Presence as Comforting Presence}

The affirmative aspect of nursing presence has been used since the beginning of modern nursing. Florence Nightingale established a nursing presence in the military hospital during the Crimean War in doing and in being [26]. In any given situation, presence in nursing is important. The nurse's presence has an impact of how patients perceive them. An impression of how a nurse conveys their words, exhibits their behavior and shows genuineness in every encounter of care helps patients with their coping and recovery. Fahlberg and Roush ([40], p. 14) defined nursing presence as "a holistic and reciprocal exchange between the nurse and patient that involves a sincere connection and sharing of the human experience through active listening, attentiveness, intimacy, and therapeutic touch, spiritual exploration, empathy, caring and compassion, and recognition of the patient's psychological, psychosocial, and physiological needs"

With comforting presence, the nurse's presence projects and emits a sense of positivity, openness and calmness without being judgmental of the patient that presents itself with every encounter. Because every patient encounter is unique and transformational, the nurse must always calibrate themselves in every patient encounter so as to assess as to how they will give comforting presence to every patient. A comforting presence makes a big difference to every nursing encounter, thus, the nurse does not make a comparison of the experiences of 
every patient. Each trauma or experience should be respected in its uniqueness, thus, each story should be heard attentively as its own thing [41].

\subsection{Interconnectedness as Facilitating Togetherness}

Interconnectedness reflects the fact that people and the universe are connected in a powerful way [42]. The connection can either be physical as with physics or spiritual by reflecting a higher power or purpose. People, at any given time and place, are interconnected, interdependent and interrelated. On a larger scale, everyone is a part of a natural and social web of life that supports and sustains us. Ethically, it is the belief that we have each other's back, that we are each other's keeper, with the realization that no one is free while others are oppressed. In nursing, interconnectedness is a way of connecting with every patient, understanding that in the course of the caring experience, our lives will course through a certain web of life that makes nurses understand more of the lives of their patients. The actions of nurses will have an impact on the behavior of patients, and in the same way, the behavior of patients directs the actions of nurses with the aim of alleviating the sufferings of patients. We are all individuals with our own unique experiences. With every nursing encounter, these individual unique experiences are being laid down and unraveled.

\subsection{Mutuality as Engaging Exchange of Selves}

Like any other relationship, the nurse-patient relationship is meaningful and transformational. A healthy mutuality in a relationship involves making a commitment or an agreed goal for each other that the relationship (nurse-nursed relationship) is just as important as each individual person. It is a way of committing to understanding and being willing to meet each person's needs in ways that work for both individuals. Establishing rapport by the nurse towards the patient is a way to achieve mutuality. Furthermore, knowing the patient, aside from conducting the routine assessment establishes mutuality between the nurse and the patient. Mutuality is important as it allows the patient to be involved in their care and makes the nurse more appreciative of the uniqueness and the individuality of the patient being cared for. A mutual relationship fosters a more positive attainment of the goal of care being set.

\subsection{Mindfulness as Transforming Nursing Experiences}

Mindfulness in nursing is a transformative process, where one develops an increasing ability to experience being present with awareness, acceptance, and attention [43]. Influenced by 2600 -year-old Eastern Buddhist Philosophy, mindfulness was taught as a means to alleviate human suffering [44] and cultivate compassion [45]. As compassion is central to nursing, the alleviation of suffering is a universal concern, particularly relevant in the field of health care where there is extensive contact with the suffering, and additionally healthcare providers themselves struggle to maintain their own health and well-being in the midst of car- 
ing [43].

Mindfulness enables the nurse to ground themselves with different nursing situations and make them be aware of how to alleviate the sufferings of every patient in any given situation. A nurse is able to fully pay attention to a situation at hand without being judgmental, but rather having an open mind to find ways to alleviate any suffering that is experienced by the patient. Nurses must use their personality in the encounter with patients. Each event and encounter is unique. Therefore, it is important to make time for an encounter, that is, so that one does not rush through it and encounters the person in a careless manner and turn the situation into more of an interview than a human encounter [46].

\section{The Practice Process of Nurse-Nursed Dyadic Relationship}

The practice process is discussed from the viewpoints of the assumptions and the attributes of the theory. There are four processes of practicing nursing, namely, 1) Knowing as appreciating relational moments, 2) Reflecting as engaging in moments, 3) Realizing patterns of living moments, and, 4) Transcending as celebrating moments.

\subsection{Knowing as Appreciating Relational Moments}

Knowing is an important aspect of understanding the "who" and "what" of a person. It is a divergence of understanding which involves both the nurse and the nursed. Nurses engage in several encounters with different individuals, with differing concerns and dealing with such, the nurse in a given situation must be able to assimilate themselves with the diversity of every individual they are with. Carper's [47] Fundamental Patterns of Knowing in Nursing is very instrumental in the knowing of a person. Knowing of oneself is essential as one engages in knowing of others. Hall [48] noted how the nurse needs to learn who he is so that his own concerns will not interfere with the patient's exploration of his concerns.

Johns [49] pointed out that the knowing of self involves three inter-related factors: 1) the perception of the self s feelings and prejudices within the situation; 2) the management of the self's feelings and prejudices in order to respond appropriately; and 3) managing anxiety and sustaining the self. Furthermore, Johns [49] described that a personal way of knowing is necessary to "be connected" within the situation. Personal knowledge empowers the nurse to experience the reality and uniqueness of their patients at a moment in time [47]. This is the kind of knowing that is relative in the promotion of wholeness and integrity in the personal encounter, emphasizing the achievement of engagement rather than detachment, and it denies a manipulative, impersonal orientation.

There are three phases in the process of Knowing as Appreciating Relational Moments, namely: 1) Appreciating Persons as wholes and complete in the moment, 2) Realizing Individuality in Selfhood; and 3) Acknowledging Differences of Being. 


\subsubsection{Appreciating Persons as Wholes and Complete in the Moment}

In this practice process identified and described are ways of purposeful engagements in the nurse-nursed dyadic relationship in order to appreciate persons as wholes and complete in the moment. It involves appreciating persons without any biases or prejudices, and accepting them as they are without any consideration of backgrounds or human factors that influence their reflections of humanness in themselves.

\subsubsection{Realizing Individuality in Selfhood}

Realizing individuality is knowing persons as unique individuals with their own sets of cultural beliefs and sense of understanding. The process of coming to know the unique nature of each person constitutes the essence of nurse-patient relationships [47]. From the words of Carl Jung, individuation is the development of consciousness, a process by which an unformed person develops into a unique individual [50]. It is the uniqueness of the individual and their ability to make choices that characterizes the authentic human being.

\subsubsection{Acknowledging Differences of Being}

Acknowledging differences is considering that a person has certain characteristics that are not the same with other individuals; that a person's behavior and actions are relative to prior experiences and it does not dictate the reality of the person. When the nurse enters the nurse-nursed relations, they truly open up to the experience of the nursed, regardless of diversity of background, beliefs and values, and healing occurs. Patterson and Zderad [51] pointed out that despite the disease, diagnosis, or health condition focus of the health care system, the work of nursing is to create an environment that promotes healing by honoring the unique worth and values of each human being.

In the same manner, the nurse undergoes the three phases, so as to be able to open up embracing the opportunity to engage and to connect with the nursed. The nurse is able to clarify their own understanding of self as it progresses into the nurse-nursed relations, and is able to point out their own set of beliefs and understanding that better guides the nurse in caring for the nursed. Somerville [52] noted that "when patient felt known by their nurses they experienced being 1) Recognized as a unique human being; 2) Felt safe; 3) Experienced a meaningful personal connection with their nurses; and 4) Felt empowered by their nurses to participate in their care.

\subsection{Reflecting as Engaging in Moments}

Somerville and Keeling ([53], p. 42) noted that "nurses are constantly being encouraged to be reflective practitioners."Reflecting constitutes a personal kind of learning in response to experience, situations, events, or new information. In a clinical setting, a nurse caring for the nursed with (a) certain condition/s or concern/s carries out the basic nursing measures such as the vital signs taking, giving of medication, assisting with certain health needs, and giving relevant 
health education.

This is also concrete in other areas, some of the specialized areas. Because of what the nurse has done to the nursed, eventually, a feedback will be expected wherein the nursed is thankful to the service of the nurse. This is one way of showing what caring in nursing is. However, is the nurse really doing what they are expected to do with the nursed? At some point in the nursing encounter, has the nurse really understood and known the person fully?

Reflecting as engaging in moments has two phases namely: 1) Relating experience, and 2) Immersing. The nurse is moving into understanding the nursed, as to Being with the nursed. This is the plunging into the pool of experience, never knowing the uncertainty therein. A nurse going into knowing of self is brought into the world of the nursed.

\subsubsection{Relating Experience}

In Relating experience, the nursed opens up their world to the nurse by opening the doors of realities. Somerville [52] noted that the nurses have the ability of the nurse to understand the meaning of the event within the context of the individual's life which enhances the possibility of well-being".

\subsubsection{Immersing}

Immersing is involving oneself deeply in a particular activity or situation. It is a way of dipping in or submerging oneself in the realities of the lives of others. If one immerses oneself in the nursing encounter, it implies completely involving oneself in the relations, spending time and giving of self to make the encounter more meaningful. In Immersing, the nurse journeys with the nursed and discovers several realities of the world of the nursed. It is being there to really understand the profoundness of the experience.

Immersion experiences are a form of experiential learning which typically involve intense educational instruction and exposure to complex social issues, often taking students outside of the comfort zones to critically examine their own pre-conceived notions and biases [54]. Immersing is a form of experiential learning. Carper [47] noted that a nurse, though experiential learning and reflection, initiates to become intuitive and draws upon the collective wisdom gained through personal encounters, and is able to anticipate individual patient and family responses and patterns across populations that capture responses to emerging issues.

It is very likely that nowadays, nurses are more into acts of caring but not into the values of caring. It should be that the nurse puts much emphasis on reflecting on the things that were done to the nursed, and whether or not the nurse has celebrated the wholeness of the nursed in their nursing encounter. Paterson and Zderad [51] pointed out that humanistic nursing encourages reflection; that reflection-being a learned process-can help enhance the experience of the nurse and prepare them from similar situations in the clinical environment or whichever setting they are in. The ability to be with and travel with the nursed in the 
routine of living is often overlooked, but is an essential part of the professional life of a nurse.

\subsection{Realizing as Patterns of Living Moments}

As one comes out from the depths of the encountering nursing experience, there is a period of reliving the experience so as to better see the reality of the event that occurred. At some point, the nurse goes into Distancing in which they are looking at the encountering nursing experience from a more panoramic view; seeing the situation from a wider perspective.

Realizing enables the nurse to look at the situation with consideration to finer details that contributes fairly to fully appreciate the wholeness of the nursed. It is like having a quick flashback of what had occurred, what was done, and how communication was best facilitated in the encountering nursing experience. It is a matter of building up a whole new picture out of the bits and pieces of details that have occurred prior to this phase, creating a new unified image of the encountering.

\subsection{Transcending as Celebrating Moments}

Transcending is a celebration of the wholeness of the person. It is the artful transformation of the experience into a meaningful whole and is growth facilitating. Full appreciation of the person is a deepened understanding of unfolding a new and more meaningful experience that is relevant to all dimensions of a person. Self-transcendence as noted by Reed [55] is the multidimensional expansion of self-conceptual boundaries: inwardly (e.g. through introspective experiences), outwardly (e.g. by reaching out to others), and temporally (whereby past and future are integrated into the present).

Furthermore, Reed [55] noted that self-transcendence is a fluctuation of perceived boundaries that extends the person (or self) beyond the immediate and constricted views of self and the world. Somerville [[52], p. 21] noted that "the nurse-nursed is a vehicle to transcend bias and experience the uniqueness and value of each human being; the basis of this relationship is the nurses' belief that each person has inherent worth and through the nurse-nursed relationship the nurse experiences, honors, and bears witness to the nursed' worth."

The nursed embarks on a new meaningful journey with a sense of happiness, pleasure, fulfillment, and more accepting disposition to events and situations that occurred or are still to occur. The nurse facilitates this engaging togetherness with the nursed in attaining transcendence, helping the nursed grow in the process and attain an experience that is more meaningful and valuable enhancing wholeness in any given situation. In relation to this, Newman [[33], p. 67] pointed out that "the goal of nursing is not to make people well, or to prevent their getting sick but to assist them using the power within as they evolve toward higher levels of consciousness."

Figure 1 illustrates the model of the practice process showing the relationships 


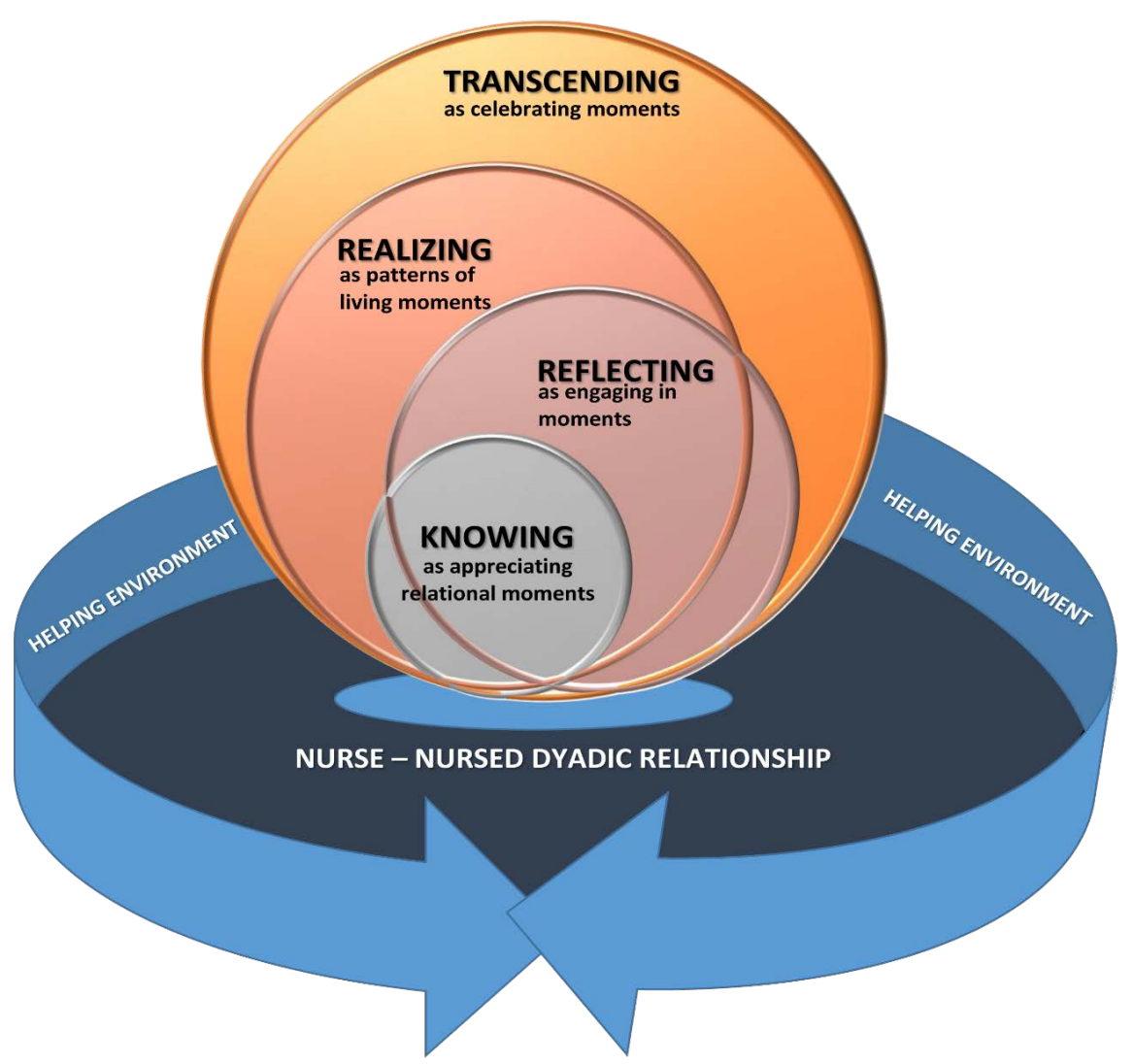

Figure 1. A model of the practice process of the theory of encountering nursing in a nurse-nursed dyadic relationship.

of the four practice processes of the theory of Encountering Nursing, namely, 1) Knowing as appreciating relational moments 2) Reflecting as engaging in moments 3) Realizing patterns of living moments and 4) Transcending as celebrating moments.

The nurse and the nursed are represented as circles since they are whole beings from moment to moment. In contrast to the traditional nursing process of Assessment, Planning, Intervention and Evaluation, [56], the theory grounds the practice process as not only prescriptive and predictive, but more importantly, as facilitating person-centered care as reflected in the model that is structured in a non-linear pattern.

Strogatz [57] pointed out that unlike a linear system, non-linear systems cannot be broken down into parts; this is why most nonlinear systems are impossible to solve analytically. Relative to the Complexity Theory, this theory is developed in such a manner that it embraces the idea of non-linearity and disproportional effect. Williams [58] noted that observations variables do not plot along a straight line and response is not proportional, and that the lived experience of nursing supports these ideas.

The four practice processes of nursing are represented with four dynamic circles that encompass the nurse-nursed interaction, at the center of the model. The process of nursing encompassing the nurse-nursed interaction is embedded in 
an environment that is considered a helping environment. It is not explicit as to the environment in which encountering nursing occurs; however, it is important to note that this model anchors on a helping environment which is made beneficial to both the nurse and the person being nursed. A helping environment creates a universe full of positivity and a sense of goodness that fosters a meaningful and transformational encountering in a dyadic relationship between the nurse and the nursed.

The practice process is initiated as the process of Knowing as appreciating relational moments in which the nurse knows the "who?" and "what?" of the person being nursed makes a good understanding of oneself. Developing a better understanding of oneself may improve one's capacity to better understand the thoughts and feelings of other people. Knowing is a dynamic process from personal reflections leading to a transformation as the individual continually connects and interacts with the world.

Carper's [47] fundamental patterns of knowing in nursing are instrumental in knowing persons as declared in this theory. Knowing of oneself is essential as one attempts knowing of others. Accordingly, every relationship is precious and unique in the sense that something can be yielded out of it, but considering knowing persons for real helps us to adjust our expectations and to maintain a more fluid relationship. To really know a person involves a certain amount of time spent, a sharing of intimate moments in different situations to discover both the positive and negative side of the person. Aside from the basic information that is being gathered during assessment, knowing more of the person being nursed brings them a feeling of being wanted and being appreciated.

Going through the process, it leads to Transcending as celebrating moments which is a celebration of the wholeness of the person and is an artful transformation of the experience into a meaningful whole and is growth facilitating. Recognizing persons as whole and complete in the moment within any situation of care means understanding and acknowledging their experiences, hopes and expectations, which may mean considering future uncertainty, feelings of loss, guilt or shame and feelings of being morally judged or blamed by any other healthcare professionals. Sensing and responding to the needs of a person creates an important underpinning to the concept of personalizing and developing a unique, patterned and mutual relationship that is tailored to fit the person being nursed. Whereas Evaluation in the traditional nursing process looks into the effectiveness or the outcome of the plan of care done to patients, Transcending as celebrating moments looks into the wholeness and the well-being of the nursed after the meaningful nursing encounter, of how a dyadic relationship between the nurse and the nursed is thoroughly affirmed.

\section{Illustrating the Practice Process: The Carousel of Nursing Encounter}

What about encounters? These are events that take place in a nurse's day to day 
life. The encounters between a nurse and the person being nursed in need of health care have been described as fundamental in nursing. These encounters can take place face-to-face in physical meetings and through meeting via distance-spanning technology [27]. As with encounters, it is not just a simple meeting of individuals, rather, it is a meeting that brings about a certain kind of change; in that in every encounter, something happens. With every nursing encounter, something happens between a nurse and the nursed. This theory holds that a nursing encounter is not simply a meet up or a conversation, but rather, it is a meaningful interaction that celebrates the wholeness of a person.

It is imagined that the process of nursing in the theory is recursive, non-linear. Thus, it is likened to the carousel. The carousel is one of the many rides seen in an amusement park; it goes around in circles. Well-lit, ornate and with beckoning melodies-carousels are part of everyone's childhood [59]. Most people who have had a carousel ride share an experience that is worth remembering. The high that one gets, at going round and round, the feeling of seeing the world whizz past, letting go of your worries, immersing yourself like the child that you have forgotten to be and enjoying the butterflies that get created in your stomachmakes the carousel a great bait for adults as well. There are constant movements; the ups and downs, the rounds and rounds. One goes through a myriad of experiences and emotions with every rotation. It is like the biggest show is happening within you [60].

Comparably, it is said that life is made of ups and downs. The highs and lows are integral of what life is all about. Every day in our lives, we make memories and we create experiences. As the Greek Philosopher Heraclitus said, "change is the only constant in life" [60]. Change is a constant thing that happens in every second of our lives. We are dynamic in nature; we simply are not the same as yesterday. That is why every moment of a person riding a carousel is a unique experience that brings meaning to the person. The number of rotations is limited and there is a fixed time setting. We may be riding the carousel with glee or cowering with fear or would have just stopped out of fear before starting to enjoy it-in all cases, it will stop. Many of us will be eager to get off, while many would want to stay longer. It doesn't matter. The most important thing is that it is one of the best encounters you had in life that you will find meaningful and unforgettable. But, when still in the ride, it brings a certain feeling of happiness and celebration that gives comfort to the one riding it. This is how encountering nursing is portrayed, something that is recursive and brings about a meaningful and transformative feeling to the nursed.

The Carousel of Nursing Encounter is a visual representation of the dyadic relationship between the nurse and the person being nursed.

Visualizing Figure 2, it is obvious that every loop represents a nursing encounter, and each small circle represents a process of nursing. Circles (or loops) are slightly overlapping (see Figure 2). Each loop represents every nurse-nursed interaction. The structure of the diagram is flexible, in such a way that the sizes 
of the loops at times are not uniform in size (could be small or big) because every nurse-nursed interaction is unique in its own way.

The recursive loops are being interpreted in the sense that an interaction or situation exist only when the nurse and the nursed are interacting. No one creates the nursing situation except the nurse and the nursed as they intermingle with each other. The "carousel" is in the shape of a circuitous, recursive pattern which symbolizes infinity, never ending. The circle has always had magical properties. It is said to be the purest and most profound symbol in existence. It has no beginning and no end. Like wheels, carousels imply motion: cyclical, repetitive motion and ups and downs.

A carousel represents enjoyable thoughts or situations that keep repeating, emotionally going in circles while feeling good reliving something you enjoyed in the past over and over. The nurse in an encounter brings the nursed to a feeling of celebrating the moment and the hope is that every nursing encounter should bring about a sense of enjoyment to the person being nursed.

The process of nursing as represented by the loops in the model is depicted in a recursive manner because there is repeated application of the process of nursing in every nurse-nursed interaction. This also portrays continuity and interconnectedness from one interaction to another interaction. Holopainen, Nystrom \& Kasen [61] defined a caring encounter as an encounter between two equal persons wherein one is nurse and the other is patient. They encounter in mutuality, in true presence, and both have allowed themselves to be the person they are. In the theory developed, it highlights a dyadic relationship that occurs in any situation of care.

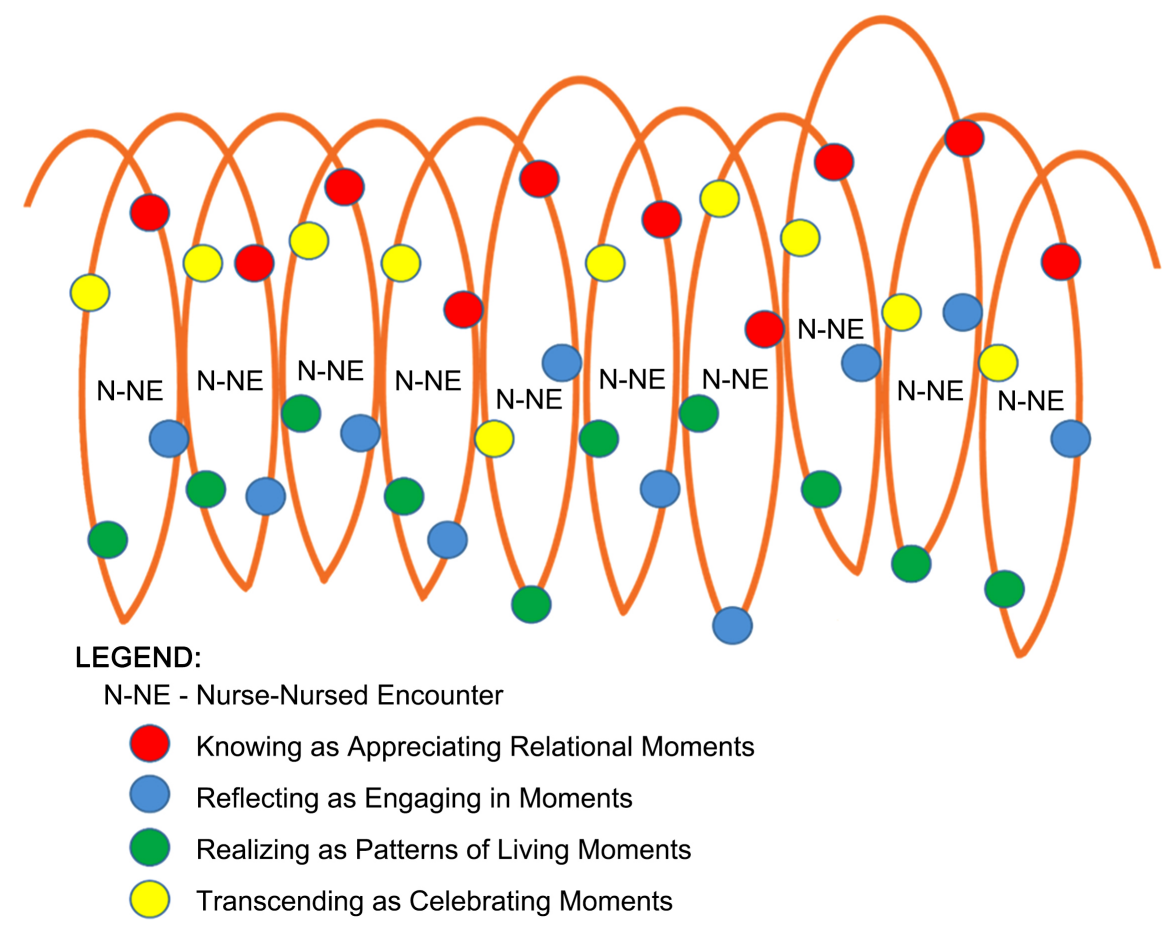

Figure 2. The carousel of nursing encounter. 
Table 1 shows a summary of the practice process of nursing encounter in a nurse-nursed dyadic relationship. It shows the four processed of nursing in the theory according to description, attributes and consequences. Accordingly, the process of nursing is described as follows: 1) Knowing as Appreciating Relational Moments is understanding the "who" and "what" of the person, 2) Reflecting as Engaging in Moments is moving into understanding the nursed, to Being with the nursed, 3) Realizing as Patterns of Living Moments is seeing the situation from a wider perspective, and, 4) Transcending as Celebrating Moments is the artful and meaningful transformation of the experience. Each process is characterized by different attributes namely: 1) presence as comforting presence (Knowing), 2) interconnectedness as facilitating togetherness (Reflecting), 3) mutuality as engaging exchange of self (Realizing), and 4) mindfulness as transforming nursing experience (Transcending).

\section{Nursing Encounters within the Nursing Environment}

Florence Nightingale founded modern nursing on the tenet that the role of the nurse was primarily to modify the environment in ways that enhanced health and healing [62]. Nightingale used the term environment in her writing implicitly and defined and described in detail the concepts of ventilation, warmth, light, diet, cleanliness, and noise, which are components of the environment [[21], p. 75]. In Nightingale's view, any factor that can affect the health of the patient and the health of the public was relevant to nursing practice. Nightingale precisely defined her concepts taking into consideration the patient's environment specifically listing physical, emotional, or social aspects and apparently assumed that all of these aspects were included in the environment.

In the context of nursing environment in the theory of Nursing Encounter in Nurse-Nursed Dyadic Relationship, there is no definite setting or locale, rather it is considered "universal", which could refer to an occurrence, an event, or any

Table 1. Summary and analysis of the practice process of nursing encounter in nurse-nursed dyadic relationship.

\begin{tabular}{|c|c|c|c|c|}
\hline Processes & Knowing & Reflecting & Realizing & Transcending \\
\hline $\begin{array}{l}\text { Description of } \\
\text { Process }\end{array}$ & $\begin{array}{l}\text { Understanding the who } \\
\text { and what of a person } \\
\text { - Appreciating Persons as } \\
\text { Wholes and Complete } \\
\text { in the Moment } \\
\text { - Realizing Individuality } \\
\text { in Selfhood } \\
\text { - Acknowledging Differences } \\
\text { in Being }\end{array}$ & $\begin{array}{l}\text { Moving into understanding } \\
\text { the nursed, as to Being } \\
\text { with the nursed } \\
\text { - Relating Experience } \\
\text { - Immersing }\end{array}$ & $\begin{array}{l}\text { Distancing-seeing } \\
\text { the situation from a } \\
\text { wider perspective }\end{array}$ & $\begin{array}{c}\text { Artful and meaningful } \\
\text { transformation of the } \\
\text { experience }\end{array}$ \\
\hline $\begin{array}{l}\text { Attributes of the } \\
\text { Process }\end{array}$ & $\begin{array}{l}\text { Comforting } \\
\text { Presence }\end{array}$ & $\begin{array}{l}\text { Facilitating } \\
\text { Togetherness }\end{array}$ & $\begin{array}{l}\text { Engaging Exchange } \\
\text { of Self }\end{array}$ & $\begin{array}{l}\text { Mindfulness as } \\
\text { Transforming Nursing } \\
\text { Experience }\end{array}$ \\
\hline $\begin{array}{l}\text { Consequences of } \\
\text { the Process }\end{array}$ & $\begin{array}{l}\text { An Appreciating of } \\
\text { Relational Moment }\end{array}$ & $\begin{array}{l}\text { An Engaging } \\
\text { in the Moment }\end{array}$ & $\begin{array}{c}\text { Patterns of } \\
\text { Living Moments }\end{array}$ & Celebrating Moments \\
\hline
\end{tabular}


situation that occurs anywhere as long as there is nurse-nursed relations. Florence Nightingale's often quoted beliefs "that nature alone heals" and that the role of nursing is to put the patient in the best environment for the natural reparative process to occur date back to the ancients.

The integration of environmental health concerns into nursing's scope or practice and the profession's philosophy of health and health care also illustrate nursing's historical and continued concern about environmental influences on human health [63]. Hence, in the ThENNDyR, the environment is considered to be a helping environment that is transformative and celebrates the wholeness of the person.

\section{Implications for Practice, Research, and Education}

\subsection{Nursing Practice}

One of the major roles and responsibilities of nurses is to talk with and care for patients. Nurses, who are always on the frontline, experience firsthand the worries, fears, hopes, and care goals of different patients or a family member. In this manner, they should always be the patient's advocates. Looking into ways to positively improve the patient experience-which many of the healthcare professional are going into-can be quite challenging, most especially in an environment where it is continually evolving. Furthermore, there is an added pressure on nurses knowing that it they who take the lead in patient experience.

Walivaara, Savenstedt \& Axelsson [27] noted that the encounter between registered nurses and persons in need of healthcare has been described as fundamental in nursing care. A strong view expressed in the literature is that face-toface encounters are important and cannot entirely be replaced by remote encounters. Being personal and professional at the same rime could encourage nurses to focus on doing and being during the encounter. Westin [64] pointed out that the challenge to balance between being a social and professional person is to balance being private and being close, to respect integrity and privacy. Despite the variation in factors and situations, a common thread in a nurse's experience is that knowing the person is an important facilitator for the encounter.

Nurses in today's healthcare environment are tasked with more responsibilities than they were in the past [65] and are experiencing a certain degree of burnout. With the advances in health care, protocols and guidelines in patient care are revolutionized in which nurses follow more rigid processes and procedures for patient care. Nurses are tasked with doing electronic charting, hourly rounding, bedside shift reports, patient whiteboards, coordination with other members of the health care teams, addressing family member's concerns on patient condition and many other tasks they have to attend to throughout the day. Knowing that each task is relevant to the patient's recovery, if nurses are not able to connect tasks with building patient relationships, the nurse-nursed (patient) relationship may be hampered, in which case it is likely to negatively impact patient experience. 
To bridge this gap, nurses need to make sure they are humanizing the care they provide by considering how they engage with patients and family members, convey and communicate information effectively, and ensure care is provided in a timely and efficient manner. Despite this circumstance, as a way to show compassion, nurses must take time to know their patients, for them to better understand the patient, to make sure that the patient is not just being "cared for" but is also being "known for". Fueled by empathy and compassion, nurses do not just recognize the need to perfect the patient experience-they encompass the heartfelt desire to make it happen, thus, seeing their patients as people first-friends, family members and neighbors [66]. Each encounter with a patient (nursed) is unique and should be based on what the patient expresses, on the patient's need, not on the nurse's preconceived ideas [46].

\subsection{Nursing Research}

It is known that nurses have encounters with patients day-to-day. Though there are reports of nurses in their different encounters with patients, it is not being explored further as to nurses engaging in knowing their respective patients. Deficiencies in knowing the significance of encounters with patients are common. Exploring the different nursing encounters between a nurse and the nursed should be given much consideration, looking into the patterns and meanings that emerge from these nursing encounters. These outcomes are important in better structuring the care for certain patients with specific needs.

In nursing and caring research, the concept of "caring encounter" and in the same manner that of "nursing encounters" is often used without further reflection on the meaning of the concept [62]. Encounters are, however, continuously and regularly taking place in the world of nursing, an observation which calls for a clarification of the concept. The nurse needs to be aware of the patient's vulnerability in their life situations and take this into account in the care [66]. Understanding the realities of every nursing encounter between the nurse and the nursed in varied nursing situations will contribute largely in advancing the knowledge in nursing as a discipline, for these are firsthand experiences that help in shaping the human caring experience into a more meaningful and effective one.

\subsection{Nursing Education}

The clinical learning component is a part of the formal nursing education process and the learning that occurs in the clinical environment presents a challenge that may cause students to experience increased stress and anxiety [67]. An important consideration is that nursing instructors and preceptors should look into their students' descriptions of their experiences concerning their nursing encounters which may assist in preparing, supervising, and providing feedbacks to students before, during and after exposure to different clinical areas.

Globally, nursing education has significantly changed in the last decade placing more emphasis on student learning being focused in the clinical environ- 
ment. Kaldal, et al. [67] pointed out that the purpose of nursing education is to provide the necessary theoretical knowledge and clinical experience to facilitate and prepare nursing students to progress into the professional role of a nurse. With the current advances in health care, clinical settings become progressively more stressful as new procedures and technologies are introduced; thus, the focus is on achieving the competencies expected from every nursing student and, consequently, the learning becomes more content-based rather than patient-centered-based. In this context, student nurses most likely handle patients in terms of an application of what is being learned and expected from them, without looking into learning by knowing the patient as a whole person.

It is the aim of nursing schools to provide its students with both theoretical learning and clinical experiences that help in shaping them to become professional nurses who must be prepared to meet diverse patients' needs, functions as leaders, and advance science that benefits patients and the capacity of health professionals to deliver safe, quality patient care [68]. The nursing curriculum being practiced in nursing schools aims to teach student how to become competent nurses equipped with the necessary knowledge and skills. However, nursing education administrators should look into incorporating courses that will teach students how to better know and understand their patients, rather than thinking of them as recipients of care. Nursing schools should modify their classification of patients as mere recipients of care, and consider them rather, as participants in the caring experience. By doing this, the students' experience will be much more enriching and will enhance their relationship with their respective patients. With nursing students developing the skills in knowing the patient, a better patient care outcome is fostered.

As student nurses in a clinical learning setting, students should try to know the patient as best they can. The usual procedures of conducting health assessments, taking health history, doing vital signs, and any other routine activities and nursing procedures are being taught effectively in the classroom setting and being reinforced during simulation and return demonstration activities. However, students should be educated on how to handle patients in any given nursing situation, taking particular consideration in knowing the patient beyond what is solicited from conducting the routine health assessment. The skill of knowing should be taught and initiated in nursing schools so that when these students become registered nurses, it will be easy for them to handle patients with varied history and health needs. Attending to patients should always be a priority, and those day-to-day interactions as part of any related learning experiences will serve as grounds for learning opportunities.

\section{Conclusion and Recommendations}

The nurse-nursed encountering and dyadic relationship constitute a vehicle to transcend bias and experience the uniqueness and value of each human being. The basis of this relationship is the nurse's belief that each person has inherent 
worth and through the nurse-nursed dyadic relationship, the nurse experiences, honors, and bears witness the patient's worth. Although studies exist that use the concepts of knowing, reflecting, realizing, and transcending, there is a need to assess the testability of this theory to different nursing settings.

\section{Illustrating the Practice Process through an Exemplar}

The following practice exemplar illuminates the practice process of nursing guided by the theory of Nursing Encountering in Nurse-Nursed Dyadic Relationships.

The Nursing Encounter.

A nurse is caring for Rachelle, a 75 year old female patient, diagnosed with Stage IV breast cancer. She was informed by her attending physician that she has only three months to live. Nurse Gigi is the one assigned to attend to the care of this patient. Knowing this, Gigi prompted herself that this kind of patient with the said condition has the tendency to be emotional and sensitive; thus, she made herself aware of how to approach and converse with the patient.

The nurse introduced herself to the patient.

Nurse: "Hello Ma' am, I am Gigi. I will be your nurse for today."

As she was talking, she observed that the patient just stared at her and said no word at all. The patient looked weak but somehow continued to listen as the nurse was talking. Having observed this behavior from Rachelle, Nurse Gigi was mindful of her actions and her words as she was speaking to her. However, she continued to smile and asked her if there was anything she needed.

The significant other informed the nurse that he will have to leave to buy her medicines. A few minutes later, the patient started to converse with the nurse:

Patient: "Hello Nurse Gigi. I am Rachelle. I am sorry I was silent a while ago. I just don't like to talk with him (SO) around."

Nurse: "That is okay Ma' am, I do understand you. I believe that you are going through something now. I believe that your attending physician came here a while ago and that he has informed you about your condition. How are you feeling now? What is important to you now?"

Patient: "Oh yes! Doctor Matthew came here a while ago. His news on my condition was very shocking. I was in utter disbelief but I tried to retain my composure. Upon knowing that I only have 3 months to live, I was sad! But now, I am starting to learn to accept the reality of my condition. I know it takes time, but I know I will be doing fine with it. I really was hoping that I could have more years to live, but I guess everything nears to an end. I have been with cancer for many years now. It really indeed was a constant struggle, a battle to survive every day. I am already 75 years old. I have lived enough. My children are already stable with their own lives."

Rachelle, the nursed, started to cry and held the hand of the nurse. The nurse held the hand of the nursed and got closer but remained calm. Rachelle contin- 
ued to talk to the nurse about her concerns and so many things. At this point, she was feeling more comfortable in opening herself up to Nurse Gigi. The nurse managed to stay with her and realized that her presence and time at that moment were needed by the patient.

Nurse Gigi realized that in instances such as this, if a nursed is feeling in distress or is in a state of pain or loss, it is not necessary to give them space, rather, our comforting presence is much needed and appreciated at the moment. After minutes of conversation the nursed became more calm and was already smiling. The nurse was appreciative that the nursed was able to relate this to her despite the fact that the issue at hand was something sensitive.

Before going back to her work, nurse Gigi paused for a moment, and recalled their encounter with Rachelle, how the patient's mood changed as she related her feelings and concerns to her until she was calmer and got hold of the situation, and how she remained calm and more open to what Rachelle was sharing to her. Moments later, the nurse was already at the end of her shift.

Before the nurse left the hospital, she visited Rachelle to bid goodbye. Rachelle greeted her with a smile and was in a light mood and the patient was already conversing with her significant other. The nursed introduced the person with her as her nephew. The nurse left and the nursed (Rachelle) continued to talk with her nephew. The nurse, then realized that it's not about what you usually do to your patients like doing physical assessment, taking vital signs, giving of prescribed medications, a part from what is superficial in doing caring in nursing to various nursed, but it is a matter of how you have known every patient you care for and how you have touched their lives even just for a moment, how you take time to converse with them and 'being with' the nursed in their journey with their condition.

In encountering nursing in a nurse-nursed dyadic relationship, there is a person who complements to the uniqueness of another person, where there is a synchronicity of time, space, and humanness, a transformation of the human caring experience.

\section{Analysis of the Nursing Encounter}

To better understand how nursing is practiced using the practice process, the given exemplar of the nursing encounter is analyzed according to the four specific processes of Knowing as appreciating relational moments, Reflecting as engaging in moments, Realizing as patterns of living moments, and Transcending as celebrating moments.

\subsection{Knowing as Appreciating Relational Moments}

Knowing as Appreciating Relational Moments has three phases, namely: appreciating persons as wholes and complete in the moment, realizing individuality in selfhood, and acknowledging difference in being,

Phase 1. Appreciating persons as wholes and complete in the moment

The exemplar has described Rachelle as a 75-year old woman, with a diagnosis 
of Stage 4 breast cancer. Gigi (the nurse) appreciated Rachelle's wholeness as a person with a devastating condition who has the tendency to be emotional and sensitive, therefore, she made herself aware of how to approach and converse with Rachelle. Gigi introduced herself by personalizing the situation, Nurse: "Hello Ma am, I am Gigi. I will be your nurse for today"

Phase 2. Realizing individuality in selfhood

The nurse at this point of the process asks "How unique is the person being nursed? What are the things that I need to look into considering the nursed is unique? In the exemplar, as she (Nurse Gigi) was talking, she observed that the patient just stared at her and said no word at all. The patient looked weak but somehow continued to listen as the nurse was talking. Noticeably, Gigi understood that Rachelle has something going on in her mind at the moment she was talking to her. With the condition Rachelle is in, Gigi realized that this is her unique way of reacting to her present situation. Nurse Gigi kept on talking without making the situation awkward for Rachelle.

\section{Phase 3. Acknowledging differences in being}

This phase of the process guided the nurse to consider persons being nursed as having certain characteristics that are not the same with other individuals; that a person's behavior and action are relative to prior experiences and does not dictate the reality of the person. How diverse is the person being nursed? In the exemplar, it was shown that having observed this behavior from Rachelle, Nurse Gigi was mindful of her actions and her words as she was speaking to her. However, she continued to smile and asked her if there was anything she needed. The nurse in this situation should consider the different reactions and behaviors exhibited by the person being nursed. With a different background, what a nursed experienced prior to their present condition influences her understanding and reaction of health condition. The nurse should never be judgmental of the persons' behaviors, rather, be more open and see this as a prompt to plan out care that will address this concern.

At any given time, a nurse will be assigned to persons with different needs. There are times that the nurse will be assigned to a person being nursed who may be considered as easy or difficult patients. In this manner, the nurse is flexible and open to know and understand the situation of the person being nursed that will be assigned to them. In this scenario, Nurse Gigi is assigned to Rachelle who is terminally-ill with stage IV cancer. Knowing that this kind of person has a lot going on, Nurse Gigi was calm and more accepting in dealing with Rachelle. To better understand a person being nursed, nurses should be open and have a comforting presence when attending to these individuals. Knowing, aside from the usual assessing of persons, should be done by nurses as a way to seeing the persons being nursed as whole in the moment.

\subsection{Reflecting as Engaging in Moments}

Reflecting as engaging in moments is a process of nursing which is a personal 
learning in response to experience, situations, events, or new information. In this process, there are two phases as follows:

\section{Phase 1. Relating experience}

In this phase, how does the nurse create an opening that engages her world to the experience of the nursed? In the exemplar, Nurse Gigi sets the condition of the encounter by presenting a very light, open and friendly disposition. Taking time to know Rachelle more sets the rapport between the both of them. As there was a build-up of connection that occurs between the two, the silent Rachelle starts to open up to Gigi, as shown in the exemplar: The significant other informed the nurse that he will have to leave to buy her medicines. Few minutes later, the patient started to converse with the nurse:

Patient. "Hello Nurse Gigi. I am Rachelle. I am sorry I was silent a while ago. I just don't like to talk with him (SO) around."

Nurse: "That is okay Ma' am, I do understand you. I believe that you are going through with something now. I believe that your attending physician came here a while ago and that he has informed you about your condition. How are you feeling now? What is important to you now?"

Patient: "Oh yes! Doctor Matthew came here a while ago. His news on my condition was very shocking. I was in utter disbelief but I tried to retain my composure. Upon knowing that I only have 3 months to live, I was sad! But now, I am starting to learn to accept the reality of my condition. I know it takes time, but I know I will be doing fine with it. I really was hoping that I could have more years to live, but I guess everything nears to an end. I have been with cancer for many years now. It really indeed was a constant struggle, a battle to survive every day. I am already 75 years old. I have lived enough. My children are already stable with their own lives."

This event illuminated the initial interconnectedness that occurred between Nurse Gigi and Rachelle. Nurse Gigi was able to help Rachelle to open up about her experience as Nurse Gigi opens up herself to embrace Rachelle as a whole person with a unique experience.

\section{Phase 2. Immersing}

Moving on with the process, the nurse plunges through into the world of the nursed. At this point of the process, there is a strong interconnectedness that transpires between the nurse and the nurse. Having to reach this point of the process, the nurse journeys on with the nursed and discovers several realities of the world of the nursed. In the given situation in the exemplar, it can be seen that there is a strong connection between the nurse and the nursed: The nursed started to cry and held the hand of the nurse. The nurse held the hand of the patient and got closer but remained calm. The nursed continued to talk to the nurse about her concerns and so many things. The nurse managed to stay with her and realized that her presence and time at that moment was needed by the patient. After minutes of conversation the nursed became calm and was already smiling. 
It can be expected that at this point, there is vulnerability on the part of the nursed because of the openness of the experience shared, thus, the nurse should put much emphasis on reflecting on the things that were done to the nursed, if the nursed was taken care of well during this journeying.

In this scenario, it can be realized that through purposeful interaction between the nurse and the person being nursed, there is an increased understanding of the people, events, history and experiences that are meaningful in shaping the person's life. As a result of this mutual and reciprocal process, the nurse and the nursed are recognized as unique human beings as they enter into an engaging relationship.

\subsection{Realizing as Patterns of Living Moments}

Realizing as patterns of living moments enables the nurse to look at the situation with consideration to finer details that contribute fairly to fully appreciate the wholeness of the nursed. In the given exemplar, the nurse was able to capture the experience of the nursed from a finer perspective. What happened in the nursing encounter? What were the other things that the nurse was able to learn from the nursed? Was the journeying created a beautiful, meaningful encountering? It can be seen that "The nurse was appreciative that the nursed was able to relate this to her despite the fact that the issue at hand is something sensitive." This process gives the nurse an opportunity to look into what has happened, more of a flashback of what transpired in the nursing encounter. It was shown in the exemplar that "Before going back to her work, nurse Gigi paused for a moment, and recalled their encounter with Rachelle; how the patient's mood changed as she related her feelings and concerns to her until she was calmer and got hold of the situation, and how she remained calm and more open to what Rachelle was sharing to her". It is important to note that nurses in every nursing encounter should pause and look into what happened in the nursing encounter. This is a way to appreciate the experience of caring and helping and grounds the nurse to the essence of nursing in any situation of care.

Looking back at what happened during the nursing encounter, the nurse is able to see this in a wider perspective. This gives them a deeper understanding of what has occurred between them and the nursed. Nurses should take the time to pause and look into the impact of the nursing encounter and how this influences the kind of care that they can provide to better the situation of the nursed.

\subsection{Transcending as Celebrating Moments}

Transcending as celebrating moments is the artful transformation of the experience into a meaningful whole and is growth facilitating. In the given exemplar, this event occurs in which a meaningful transformation has occurred with the nursed through the efforts of the nurse in helping the nursed:

Moments later, the nurse is already at the end of her shift. Before the nurse

left the hospital, she visited Rachelle to bid goodbye. Rachelle greeted her 
with a smile and was in a light mood and the nurse saw that the patient was already conversing with her significant other.

Consequently, Rachelle had a better disposition than when Nurse Gigi initially met her when she (Rachelle) introduced the person with her as her nephew.

Having been able to witness this, Nurse Gigi left the facility, knowing that the nursed (Rachelle) continued to talk with her nephew. Considering that the nurse (Gigi) was able to facilitate a celebration of the moment, she (Gigi) then realized that it's not about what you usually do to your patients like doing physical assessment, taking vital signs, giving of prescribed medications, a part from what is superficial in doing caring in nursing to various nursed, but it a matter of how you have known every patient you care for and how you have touched their lives even just for a moment, how you take time to converse with them and "being with" the nursed in their journey with their condition. In encountering nursing, there is a synchronicity of time, space, and humanness.

In this scenario, Nurse Gigi was able to help Rachelle to have a better grasp of the situation she is in. She was weak and gloomy before, but after their encounter, Rachelle became a better person. Nurse Gigi was able to facilitate this transformation in Rachelle. The nurse facilitates the engaging togetherness with the person being nursed in attaining transcendence, helping the nursed grow in the process and attain an experience that is more meaningful and valuable that enhances wholeness in any given situation.

\section{Acknowledgements}

The authors express their gratitude to Dr. Rozzano Locsin, Emeritus Professor of Tokushima University Graduate School of Biomedical Sciences, Tokushima, Japan, for his incessant passion in nursing theory development, theory construction and in advancing the knowledge of nursing that serves as the authors' inspiration towards the development of the Theory of Encountering Nursing in a Nurse-Nursed Dyadic Relationship (ThENNDyR).

\section{Conflict of Interest}

The authors declare no conflicts of interest regarding the publication of this article.

\section{References}

[1] Mackewn, J. (1997) Developing Gestalt Counselling: A Field Theoretical and Relational Model of Contemporary Gestalt Counselling and Psychotherapy. SAGE Publications, Thousand Oaks. https://doi.org/10.4135/9781446280461

[2] Hycner, R. (1995) The Dialogic Ground. In: Hycner, R. and Jacobs, L., Eds., The Healing Relationship in Gestalt Therapy: A Dialogic Self Psychology Approach, The Gestalt Journal Press, New York, 55-66.

[3] Kramer, K.P. (2011) Dialogically Speaking: Maurice Friedman's Interdisciplinary Humanism. Wipf and Stock, Oregon.

[4] Green, C.A., Polen, M.R., Janoff, S.L., Castleton, D.K., Wisdom, J.P., Vuckovic, N., 
Perrin, N.A., Paulson, R.I. and Oken, S.L. (2008) Understanding How ClinicianPatient Relationships and Relational Continuity of Care Affect Recovery from Serious Mental Illness: STARS Study Results. Psychiatric Rehabilitation Journal, 32, 9-22. https://doi.org/10.2975/32.1.2008.9.22

[5] Holopainen, G., Kasen, A. and Nystrom, L. (2014) The Space of Togetherness: A Caring Encounter. Scandinavian Journal of Caring Science, 28, 186-192. https://doi.org/10.1111/j.1471-6712.2012.01090.x

[6] Tejero, L.M.S. (2011) The Mediating Role of the Nurse-Patient Dyad Bonding in Bringing about Patient Satisfaction. Journal of Advanced Nursing, 68, 994-1002. https://doi.org/10.1111/j.1365-2648.2011.05795.x

[7] Tejero, L.M.S. (2016) Behavioral Patterns in Nurse-patient Dyads: A Critical Incident Study. International Journal of Human Caring, 20, 129-133.

[8] Boykin, A. and Schoenhofer, S. (2001) Nursing as Caring: A Model for Transforming Practice. Jones \& Bartlett, National League for Nursing, New York.

[9] Hardin, S. and Bishop, S.M. (2017) Theory Development Process. Nurse Key. https://nursekey.com/theory-development-process/

[10] Walker, L.O. and Avant, K.C. (2011) Strategies for Theory Construction in Nursing. $5^{\text {th }}$ Edition, Pearson Education, USA.

[11] Nuopponen, A. (2010) Methods of Concept Analysis: A Comparative Study. LSP Journal, 1, 4-12.

[12] Locsin, R. (2016) Technological Competency as Caring in Nursing. Silliman University, Philippines.

[13] Parse, R.R. (1981) Man-Living-Health: A Theory of Nursing. Wiley, New York.

[14] Encyclopedia.com. (2020) Existentialism.

http://www.encyclopedia.com/philosophy-and-religion/philosophy/philosophy-ter ms-and-concepts/existentialism

[15] Sartre, J.P. (1947) Existentialism. Frenchtman, B. Trans. Philosophical Library, New York, 14

[16] (2018) All about Philosophy. Existentialism. https://www.allaboutphilosophy.org/existentialism.htm

[17] Kaufmann, W. (1956) Existentialism from Dostoevsky to Sartre. Meridian Books, New York, 12.

[18] Leddy, J.P. (1963) A Critical Analysis of Jean Paul Sartre's Existential Humanism with Particular Emphasis upon His Concept of Freedom and Its Moral Implications. University of Windsor, Windsor.

[19] Huitt, W. (2001) Humanism and Open Education. Educational Psychology Interactive. Valdosta State University, Valdosta. http://chiron.valdosta.edu/whuitt/col/affsys/humed.html

[20] David, L. (2015) Humanism in Learning Theories. https://www.learning-theories.com/humanism.html

[21] Tomey, A.M. and Alligood, M.R. (2008) Nursing Theorists and Their Work. 6th Edition, Elsevier, Singapore.

[22] Parse, R.R. (1987) Nursing Science: Major Paradigms, Theories, and Critiques. W.B. Saunders, Philadelphia.

[23] Parse, R.R. (1993) Scholarly Dialogue: Theory Guides Research and Practice. Nursing Science Quarterly, 6, 12. https://doi.org/10.1177/089431849300600106

[24] Newman, M., Sime, .M. and Corcoran-Perry, S. (1991) The Focus of the Discipline 
of Nursing. Advanced Nursing Science, 14, 1-6.

[25] Baclig, J. (2015) Life Cycle of a Nurse: Clinical Nursing Experience. AMN Healthcare, San Diego.

[26] Dossey, B.M., Keegan, L. and Guzzetta, C.E. (2003) Holistic Nursing: A Handbook for Practice. Jones \& Bartlett, Boston.

[27] Walivaara, B.M, Savenstedt, S. and Axelsson, K. (2013) Encounters in Home-Based Nursing Care-Registered Nurses' Experience. The Open Nursing Journal, 7, 73-81. https://doi.org/10.2174/1874434620130419001

[28] Locsin, R.C. and Kongsuwan, W. (2011) The Invisible Person in a Technological World of Nursing Practice. UPNAAI Journal of Nursing, 7, 27-31.

[29] Rodgers, B.L. (2005) Developing Nursing Knowledge: Philosophical Traditions and Influences. Lippincott Williams \& Wilkins, Philadelphia, PA.

[30] Locsin, R.C. (2007) Rapture and Suffering with Technologies in Nursing. International Journal for Human Caring, 11, 38-43. https://doi.org/10.20467/1091-5710.11.1.38

[31] McCormack, B. and McCance, T. (2010) Person-Centred Nursing: Theory and Practice. John Wiley \& Sons, United Kingdom.

https://doi.org/10.1002/9781444390506

[32] Selder, F. (1989) Life Transition Theory: The Resolution of Uncertainty. Nurse and Health Care, 10, 437-440, 449-451.

[33] Newman, M. (2008) Transforming Presence: The Difference Nursing Makes. F.A. Davis, Philadelphia.

[34] Hessel, J. (2009) Presence in Nursing Practice. Holistic Nursing Practice, 23, 276-281. https://doi.org/10.1097/HNP.0b013e3181b66cb5

[35] Zyblock, D.M. (2010) Nursing Presence in Contemporary Nursing Practice. Nursing Forum, 45, 120-124. https://doi.org/10.1111/j.1744-6198.2010.00173.x

[36] Boeck, P.R. (2014) Presence: A Concept Analysis. SAGE Open, 4, 1-6. https://doi.org/10.1177/2158244014527990

[37] Snellman, I., Gustafsson, C. and Gustafsson, L. (2012) Patients' and Caregivers' Attributes in a Meaningful Care Encounter: Similarities and Notable Differences. International Scholarly Research Notices, 2012, Article ID: 320145.

[38] Brush, B., Kirk, K., Gultekin, L. and Baiardi, J. (2011) Overcoming: A Concept Analysis. Nursing Forum, 46, 160-168. https://doi.org/10.1111/j.1744-6198.2011.00227.x

[39] Walker, L.O. and Avant, K.C. (2005) Strategies for Theory Construction in Nursing. $4^{\text {th }}$ Edition, Pearson Prentice Hall, New Jersey, 4.

[40] Fahlberg, B. and Roush, T. (2016) Mindful Presence: Being "with” in Our Nursing Care. Nursing, 46, 14-15. https://doi.org/10.1097/01.NURSE.0000480605.60511.09

[41] Mike, C. (2015) The Art of Comforting Presence. Internet Monk. http://www.internetmonk.com/

[42] Love. K. (2008) Interconnectedness in Nursing: A Concept Analysis. Journal of Holistic Nursing, 26, 255-265. https://doi.org/10.1177/0898010108315184

[43] White, L. (2014) Mindfulness in Nursing: An Evolutionary Concept Analysis. Journal of Advanced Nursing, 70, 282-294. https://doi.org/10.1111/jan.12182

[44] Matchim, Y., Armer, J.M. and Stewart, B.R. (2011) Mindfulness-Based Stress Reduction among Breast Cancer Survivors: A Literature Review and Discussion. Oncology Nursing Forum, 38, E61-E71. https://doi.org/10.1188/11.ONF.E61-E71 
[45] Ludwig, D. and Kabat-Zinn, J. (2008) Mindfulness in Medicine. Journal of the American Medical Association, 300, 1350-1352. https://doi.org/10.1001/jama.300.11.1350

[46] Hemberg, J. and Lipponen, S. (2017) The Caring Encounter between Patient and Nurse within a Mental Health and Psychiatric Care Context-As Described by Nurses Working in an Emergency Polyclinic. Nursing and Palliative Care, 2, 1-7. https://doi.org/10.15761/NPC.1000147

[47] Carper, B.A. (1978) Fundamental Patterns of Knowing in Nursing. Advances in Nursing Science, 1, 13-24. https://doi.org/10.1097/00012272-197810000-00004

[48] Hall, L. (1964) What is Nursing? The Canadian Nurse, 60, 150-154.

[49] Johns, C. (1995) Framing Learning through Reflection within Carper's Fundamental Ways of Knowing in Nursing. Journal of Advanced Nursing, 22, 226-234. https://doi.org/10.1046/j.1365-2648.1995.22020226.x

[50] Ravi, R. (2010) Carl Jung's Conception of Individuality. MSS Research. http://www.mssresearch.org/?q=node/557

[51] Paterson, J. and Zderad, L. (2008) Humanistic Nursing. Project Gutenberg Ebook.

[52] Somerville, J.G. (2009) Development and Psychometric Evaluation of Patients' Perceptions of Feeling Known by Their Nurses Scale (PPFKN Scale). PhD Dissertation, Boston College, Boston. https://doi.org/10.1037/t46153-000

[53] Somerville, D. and Keeling, J. (2004) A Practical Approach to Promote Reflective Practice Within Nursing. Nursing Times, 100, 42-45.

[54] Sokol, B., Marle, P., Summers, N. and Burke, J. (2015) Short-Term Immersion Experiences: Assessing for Student Learning and Attitudinal Change. Center for Service \& Community Engagement and Department of Campus Ministry.

[55] Reed, P.G. (1997) Nursing: The Ontology of the Discipline. Nursing Science Quarterly, 10, 76-79. https://doi.org/10.1177/089431849701000207

[56] Orlando, I.J. (1961) The Dynamic Nurse-Patient Relationship: Function, Process, and Principles (Pub. No. 15-2341). National League for Nursing, New York.

[57] Strogatz, S.H. (1994) Nonlinear Dynamics and Chaos. Addison-Wesley, Boston.

[58] Williams, G.P. (1997) Chaos Theory Tamed. Joseph Henry Press, Washington DC. https://doi.org/10.1201/9781482295412

[59] Balasubramanian, B.K. (2020) A Merry-Go-Round Called Life. Medium. https://medium.com/@BBharathKumar/a-merry-go-round-called-life-c742a4c4749e

[60] Singer, J. (2018) The Only Constant Is Change. PsychCentral. www.psychcentral.com/lib/the-only-constant-is-change/

[61] Holopainen, G., Nystrom, L. and Kasen, A. (2007) The Caring Encounter in Nursing. Nursing Ethics, 14, 510-521. https://doi.org/10.1177/0969733007077885

[62] Nightingale, F. (1860) Notes on Nursing. Harrison, Littleton.

[63] Pope, A.M., Snyder, M.A. and Mood, L.H. (1995) Nursing Health \& Environment: Strengthening the Relationship to Improve the Public's Health Image. The Journal of Nursing Scholarship, 28, 81. https://doi.org/10.1111/j.1547-5069.1996.tb01184.x

[64] Westin, L. (2008) Encounters in Nursing Homes: Experiences from Nurses, Residents and Relatives. PhD Dissertation. Gothenburg: Institute of Health and Care Sciences, Sahlgrenska Academy. University of Gothenburg.

[65] Cleveland Clinic (2020) Nursing's Role in Today's Patient Experience. http://www.consultqd.clevelandclinic.org/

[66] Nilsson, A. and Soderberg, S. (2015) Nurses' Views of Shortcomings in Patient Care 
Encounters in One Hospital in Sweden. Journal of Clinical Nursing, 24, 2807-2814. https://doi.org/10.1111/jocn.12886

[67] Kaldal, M.H., Kristiansen, J. and Uhrenfeldt, L. (2015) Nursing Students' Experience of Professional Patient Care Encounters in a Hospital Unit: A Systematic Review Protocol. JBI Evidences Synthesis, 13, 30-39.

https://doi.org/10.11124/jbisrir-2015-2369

[68] Institute of Medicine (US) Committee on the Robert Wood Johnson Foundation Initiative on the Future of Nursing (2011) The Future of Nursing: Leading Change, Advancing Health. National Academies Press, Washington DC. 